\title{
REGULACIÓN DE LA LIBERTAD RELIGIOSA EN EL DERECHO ECLESIÁSTICO CHILENO
}

Comentario a la legislación y actos administrativos posteriores a la ley $n^{\circ} 19.638$

\section{René Cortínez Castro}

Magíster en Derecho Público

con mención en Derecho Constitucional

Pontificia Universidad Católica de Chile

El derecho eclesiástico nacional experimentó importantes innovaciones a partir del año 1999, con la publicación de la ley N¹9.638, sobre la constitución jurídica de las iglesias y organizaciones religiosas, desconocidas casi en el ámbito, desde la promulgación de la Constitución de 1980.

Al año siguiente, el Presidente de la República dictó un reglamento para regular el registro de entidades religiosas de derecho público. Luego, afines del año 2000, se publicó el reglamento sobre asistencia religiosa en recintos hospitalarios.

A continuación, nos proponemos comentar las nuevas regulaciones en materia de libertad religiosa, y su incorporación al ordenamiento jurídico previo.

\section{EL REGLAMENTO PARA EL REGISTRO DE ENTIDADES RELIGIOSAS DE DERECHO PÚBLICO}

La ley $n^{\circ} 19.638$, sobre la constitución jurídica de las Iglesias y Organizaciones Religiosas, en el Capítulo III relativo a la personalidad jurídica y estatutos no menciona ningún reglamento, más aún, durante su discusión en el Congreso Nacional, para evitar que su aplicación dependiese de la potestad reglamentaria, se procuró que las disposiciones legales se bastasen a sí mismas.

No obstante, en la práctica, la "constitución jurídica de las iglesias y organizaciones religiosas", conforme a la nueva ley, debió esperar que el Presidente de la República dictara un reglamento en la materia.

El Reglamento para el Registro de Entidades Religiosas de Derecho Público, se contiene en el Decreto Supremo $N^{\circ} 303$, del Ministerio de Justicia, del 21 de marzo del año 2000, publicado en el Diario Oficial el día 26 de Mayo del mismo año. 


\section{Entidades Religiosas y Registro}

El Art. $1^{\circ}$ del reglamento dispone que "las entidades religiosas que soliciten su registro como personas jurídicas de derecho público en conformidad a lo establecido en los artículos 10 a 12 de la ley $n^{\circ} 19.638$, deberán sujetarse a las disposiciones...del presente reglamento".

De la norma citada se desprende que existe una confusión conceptual en las disposiciones del Reglamento, entre las "entidades religiosas" y las personas jurídicas que estas pueden constituir.

Conforme al Art. 10 de la ley $n^{\circ} 19.638$, las entidades religiosas pueden constituir personas jurídicas, organizándolas en conformidad a la mencionada ley. La norma antes citada permite a las entidades religiosas "constituir", esto es, establecer, erigir, fundar, una persona jurídica diversa, no son las entidades religiosas las que se inscriben.

Esta interpretación es coherente con las siguientes disposiciones de la ley $n^{\circ} 19.638$ :

a) El inciso segundo del Art. $9^{\circ}$, que distingue claramente entre las entidades religiosas y las personas jurídicas que ellas constituyen, al disponer que: "Las entidades religiosas, así como las personas jurídicas que ellas constituyan en conformidad a esta ley, no podrán tener fines de lucro".

b) El Art. 12 que en su inciso $1^{\circ}$ dispone: "en los estatutos o normas propias de cada persona jurídica que se constituya en conformidad a las disposiciones de esta ley deberán contenerse aquellos elementos esenciales que la caracterizan ...".

c) El Art. 17 según el cual, "las personas jurídicas de entidades religiosas regidas por esta ley tendrán los mismos derechos, exenciones y beneficios tributarios ...".

d) El Art. 20, que reconoce la personalidad jurídica de las iglesias, confesiones e instituciones religiosas que gozan de ella a la fecha de publicación de la referida ley.

Si los sujetos de la inscripción en el Registro fueran las entidades religiosas, estas gozarían de doble personalidad jurídica, la que ya poseían -reconocida en el Art. $20^{\circ}$ de la ley $n^{\circ} 19.638$ - y otra, de naturaleza pública, que obtendrían conforme a la nueva ley, situación que resultaría absurda y contraria a derecho.

\footnotetext{
${ }^{1}$ Una interpretación opuesta puede verse en: SALINAS ARANEDA Carlos, "La reciente ley chilena que establece normas sobre la constitución jurídica de las Iglesias y Organizaciones Religiosas", II Diritto Ecclesiastico Anno CXI Fasc. 2-2000, pp. 463-471.
} 
No obsta a la interpretación aquí sostenida, lo dispuesto en el inciso final del Art. 10 de la ley $n^{\circ} 19.638$, en el sentido que "la respectiva entidad gozará de personalidad jurídica de derecho público por el sólo ministerio de la ley". El tenor literal de esta norma pareciera afirmar que es la entidad religiosa la que obtiene la nueva personalidad jurídica, pero ello no es así. Por "respectiva entidad" hay que entender al ente o persona jurídica, nueva, que constituye u organiza una entidad religiosa.

Afirmar que los sujetos de la inscripción en el Registro, son las entidades religiosas, esto es, las iglesias, confesiones e instituciones religiosas de cualquier culto (Arts. $5^{\circ}$ y $4^{\circ}$ de la ley $n^{\circ} 19.638$ ) significa privar de sus efectos al reconocimiento de su estatuto jurídico, que consagra el Art. 20 de la tantas veces citada ley, y contradice la historia fidedigna de la Ley de Iglesias, ya que los legisladores manifestaron siempre que esta no tenía por finalidad regular estas realidades asociativas.

Finalmente, si se aceptara que son las entidades religiosas las que obtienen personalidad jurídica por la inscripción, ello permitiría disolverlas en conformidad al Art. 19, por sentencia judicial. Esta conclusión pugna con lo dispuesto por dicha norma cuando expresa que esta se refiere a "la disolución de una persona jurídica constituida conforme a esta ley", ya que las entidades religiosas no se constituyen en conformidad a la ley $n^{\circ} 19.638$, y es opuesta, también, a la garantía que el Art. $3^{\circ}$ de la ley consagra a favor de las entidades religiosas.

Esta confusión aparece también en otras disposiciones del reglamento: el Art. $1^{\circ}$, que se refiere a "las Entidades Religiosas que soliciten su registro como personas jurídicas de derecho público..."; el Art. $3^{\circ}$, que prohibe "suscribir el acta de constitución de la Entidad Religiosa" y los Arts. $5^{\circ}, 6^{\circ}, 10^{\circ}, 11^{\circ}$ y $12^{\circ}$.

Conforme a lo expuesto precedentemente, no resulta fácil conciliar el contenido del Reglamento, con la disposición del Art. 20 de la ley $n^{\circ} 19.638$, y el Art. $19 n^{\circ} 6$ de la Constitución Política de la República, que reconocen la personalidad jurídica de las Iglesias, confesiones e instituciones religiosas.

\section{Constitución de las personas jurídicas}

Conforme al Art. $2^{\circ}$ del Reglamento, estas entidades deberán constituirse por escritura pública o instrumento privado reducido a escritura pública. Atendidos los beneficios y protección de los que gozan las personas jurídicas que se constituyen al amparo de la ley $n^{\circ} 19.638$, consideramos que tanto esta, como el Reglamento deberían exigir la asistencia de un ministro de fe a la asamblea constitutiva.

Entre las materias que se exigen para el contenido de los estatutos, el Art. $6^{\circ}$, debió incluir los siguientes: 
a) Que si uno de los medios de que dispondrá la persona jurídica para cumplir sus fines consiste en cuotas o aportes de sus miembros, los estatutos deben señalar su mínimo y máximo, expresados en una unidad económica reajustable ${ }^{2}$;

b) Las formalidades que deben cumplir las citaciones para la reunión de sus miembros;

c) Las formalidades y requisitos de las sesiones que deban celebrarse por sus órganos colegiados;

d) La individualización de la entidad religiosa que constituye la persona jurídica, así como de sus representantes hábiles para el efecto, debiendo acompañarse los documentos que lo acrediten (Arts. 10 y 17 de la ley $n^{\circ} 19.638$ ).

El Art. $3^{\circ}$ del Reglamento prohibe a las personas condenadas por delito que merezca pena aflictiva, suscribir el acta de constitución de la entidad religiosa. Esta prohibición, que tiene su fundamento en el Art. 12 inciso final de la ley $n^{\circ} 19.638$, afecta la libertad religiosa de las personas mencionadas, y crea una discriminación que en último término las mismas iglesias suelen rechazar.

Aunque la ley $n^{\circ} 19.638$, dispone que "el Ministerio de Justicia no podrá denegar el registro" ${ }^{3}$ (Ari. 11, inciso $\left.1^{\circ}\right)$, norma que reproduce el Art. $10^{\circ}$ del Reglamento, debe tenerse presente que los sujetos habilitados para constituir personas jurídicas en conformidad al Art. 10 de dicho cuerpo legal, son exclusivamente las "entidades religiosas". En consecuencia, si quien pretende la inscripción no tiene tal calidad, la solicitud debe ser rechazada, ya que faltaría un requisito (Art. 11 , inciso $1^{\circ}$, parte final).

Consecuentemente con lo expuesto, debería corregirse el Reglamento, disponiendo que sólo podrán constituir personas jurídicas regidas por el Art. 10 de la ley $n^{\circ} 19.638$, en conformidad al mismo reglamento, las entidades religiosas, a que se refieren los Arts. $4^{\circ}$ y $5^{\circ}$ de la mencionada ley.

Como parte del proceso de constitución de personas jurídicas, el Reglamento contempla, en el Art. $11^{\circ}$, la publicación de un extracto en el Diario Oficial, del acta de constitución y de sus modificaciones si las hubiere. Dicho extracto es confeccionado por

\footnotetext{
2 Asi lo exige el Decreto Supremo ${ }^{\circ} 110$, del Ministerio de Justicia, del año 1979, tratándose de las corporaciones y

No existe claridad en la ley $n^{\circ} 19.638$, para diferenciar el "registro" y la "inscripción". Así, el Art. 10 dispone que para la constitución de la persona jurídica se requiere la "inscripción" en el registro público, y que "desde que quede firme la inscripción en el registro público, la respectiva entidad gozará de personalidád jurídica de derecho público por el sólo ministerio de la ley". En cambio, el inciso primero del Art. 11, sólo prohibe denegar "e registro".
} 
la entidad religiosa, y autorizado por el Notario que suscribió la escritura pública o que redujo a dicha escritura el instrumento privado respectivo.

El extracto deberá contener a lo menos las siguientes menciones:

a) El nombre y el domicilio principal de la entidad;

b) Fecha y número del registro;

c) Nombre de los constituyentes;

d) Los elementos esenciales que la caracterizan y los fundamentos y principios en que se sustenta la fe que ella profesa;

e) Los órganos de administración, sus atribuciones y el número de miembros que los componen, y

f) Fecha de la escritura pública que contiene los estatutos y sus modificaciones si las hubiere, la indicación del nombre y domicilio del notario que la hubiera otorgado.

Habría sido preferible que el extracto fuese confeccionado, o a lo menos autorizado, por el Ministerio de Justicia, a fin de garantizar que este cumpla con los requisitos exigidos.

Conviene recordar que tratándose de las corporaciones y fundaciones se exige la publicación íntegra del respectivo decreto supremo, el que como se sabe no ha sido redactado por los interesados.

Si se entrega a la propia persona jurídica la redacción y publicación del extracto, debieron regularse los efectos y saneamiento de la publicación errónea o incompleta.

Respecto de la letra d) del Art. $6^{\circ}$ cabe preguntarse cómo se probará la existencia del derecho propio, ya que evidentemente no podría ser creado por el ente religioso para el sólo efecto de la inscripción.

La letra f) del Art. $6^{\circ}$ del Reglamento, con relación a lo dispuesto en el Art. $6^{\circ}$ letras a) y d) de la ley $n^{\circ} 19.638$, plantea diversas interrogantes respecto de la participación de los menores de edad o pupilos en las personas jurídicas que se constituyan, respecto de su capacidad jurídica para incorporarse a estas, así como la decisión en materia de educación religiosa, especialmente después de las últimas modificaciones al Código Civil en materia de filiación.

En el Art. $5^{\circ}$ debería precisarse qué se entiende por "documentos fundamentales" y "sede principal" (¿la más importante?, ¿dónde sesionan los 
administradores?, etc). Conviene en este último aspecto, tener presente que el Art. $13^{\circ}$ letra a, obliga a incluir en el extracto "el domicilio principal", expresión similar a la de "sede principal". En esta norma aparece clara la importancia de distinguir entre la "iglesia" y la persona jurídica pública de la nueva ley, ya que podrían existir documentos reservados, o aún secretos, en una iglesia. Tampoco queda claro el plazo durante el cual deben conservarse estos documentos.

\section{ASISTENCIA RELIGIOSA EN HOSPITALES}

El Art. $6^{\circ}$ letra c) de la ley $n^{\circ} 19.638$ dispone que la libertad religiosa y de culto, con la correspondiente autonomía e inmunidad de coacción significan para toda persona entre otras, a lo menos, la facultad de "recibir asistencia religiosa de su propia confesión donde quiera que se encuentre" y que "la forma y condiciones del acceso de pastores, sacerdotes y ministros del culto, para otorgar asistencia religiosa en recintos hospitalarios" serán regulados mediante reglamento que dictará el Presidente de la República, "a través" del Ministro de Salud.

El 28 de Octubre del año 2000 se publicó en el Diario Oficial, el Decreto Supremo $n^{\circ} 351$, del Ministerio de Salud, del 12 de mayo del mismo año, que aprueba el Reglamento Sobre Asistencia Religiosa en los Recintos Hospitalarios, tanto públicos como privados.

\section{1. Ámbito de aplicación}

Conforme al Art. $1^{\circ}$ del Reglamento, sus disposiciones se aplican, "a los pacientes internados en hospitales, clínicas y todo establecimiento en que se preste atención cerrada para ejecutar acciones de recuperación y rehabilitación de la salud de personas enfermas, tanto privados como públicos, sea que integren o no el sector salud".

El reglamento se atribuye un ámbito de aplicación inconstitucional. En efecto, tratándose de establecimientos privados un decreto supremo no puede imponerles una regulación sobre acceso de ministros del culto, sólo por medio de una ley, y en los casos autorizados por la Constitución Política, pueden afectarse las garantías y derechos que la misma consagra.

Los establecimientos privados están obligados a respetar el Art, $19 n^{\circ} 6$ de la Constitución Política, y también, la ley $n^{\circ} 19.638$, pero corresponde a cada uno de ellos, dentro de este marco, conforme a su propia naturaleza y particulares circunstancias, determinar la forma en que accederán, a los pacientes, los ministros del culto. 
En los establecimientos hospitalarios pertenecientes a entidades de carácter confesional, tratándose de pacientes que han ingresado voluntariamente, y no con motivo de atenciones de urgencia, con riesgo vital, por ejemplo, debe entenderse que estos aceptan las condiciones fijadas por el establecimiento en materia de asistencia religiosa. Así, en un establecimiento católico, si bien todo enfermo tiene derecho a recibir asistencia de su propia confesión, este no podría obstaculizar aquella que se preste a los católicos allí internados.

El artículo $6^{\circ}$ letra c) inciso segundo de la ley $n^{\circ} 19.638$, entrega a la potestad reglamentaria regular "la forma y condiciones del acceso de pastores, sacerdotes y ministros del culto para otorgar asistencia religiosa en recintos hospitalarios".

En cambio, el reglamento entra a una serie de otras materias, como la forma en que debe solicitarse la asistencia religiosa $\left(\right.$ Art. $5^{\circ}$ ); el uso de los lugares de culto (Art. $\left.12^{\circ}\right)$; la acreditación de los ministros de culto $\left(\right.$ Art. $\left.10^{\circ}\right)$, etc.

Esta pretensión de regular ampliamente el tema, aparece incluso, anunciada en el único considerando del decreto, que alude a "la necesidad de regular la forma y condiciones de la entrega de asistencia religiosa en los recintos hospitalarios".

Tampoco es razonable, como parece disponerlo el Art, $1^{\circ}$, que la asistencia religiosa se deba limitar sólo a los pacientes internados, ya que los médicos, enfermeras, auxiliares y demás personal del centro hospitalario, en razón de sus funciones y empleos deben permanecer largas jornadas en este.

Su ámbito espacial de validez se extiende a "hospitales, clínicas y todo establecimiento en que se preste atención cerrada para ejecutar acciones de recuperación y rehabilitación de la salud de personas enfermas, tanto privados como públicos, sea que integren o no el sector salud".

El Ministerio de Salud, por otra parte, tampoco tiene competencias para regular la asistencia religiosa en hospitales pertenecientes a confesiones religiosas.

Tratándose de la Iglesia Católica, y las demás que gozaban de personalidad jurídica aún antes de la ley $n^{\circ} 19.638$, conviene recordar lo dispuesto en el Art. 20 de dicha ley: "El Estado reconoce el ordenamiento, la personalidad jurídica, sea esta de derecho público o de derecho privado, y la plena capacidad de goce y ejercicio de las iglesias, confesiones e instituciones religiosas que los tengan a la fecha de publicación de esta ley".

Por lo tanto, los hospitales que pertenecen a personas jurídicas canónicas se rigen por el Derecho Canónico, las normas sobre agentes sanitarios dictadas por la Santa Sede; y sus propios estatutos y reglamentos, sin perjuicio de otorgar facilidades 
para la atención religiosa de los no católicos, en conformidad a la Constitución y las leyes.

\section{Libertad religiosa}

El reglamento parece privilegiar la hipotética preferencia de aquél enfermo, que nada quiere ver u oír, en materia de asistencia religiosa, respecto del enfermo que requiere la referida asistencia.

En efecto, el Art. $6^{\circ}$ dispone que "si el enfermo comparte habitación con otros pacientes, deberá respetarse el derecho a la privacidad de éstos de tal modo de no imponerles el oír o presenciar actividades religiosas que no han solicitado".

La autoridad parece olvidar que aquellos que comparten una habitación, por encontrarse enfermos, en una comunidad forzada, naturalmente ven limitada su privacidad, y a su vez, con su sola presencia, limitan la privacidad de los otros enfermos. Así, las conversaciones con las visitas o el médico, los procedimientos médicos, etc. son percibidos por todos los demás enfermos de la habitación, y no se ha sabido que la autoridad pretenda que ninguno de ellos hable, se queje o mueva, porque alguno de sus compañeros podría verse afectado.

En materia de asistencia religiosa, lo que debe impedirse, es que se fuerce la participación de los enfermos que no la han solicitado, por ejemplo, obligándolos a unirse a las oraciones, pero, la protección de la privacidad o de la libertad de conciencia, de cada enfermo, no puede llevarse al extremo de impedir a otro rezar, en silencio, o imponerle la instalación de un biombo para ello.

En otra disposición, sólo propia de un Estado confesional represivo, el reglamento expresa que "las personas internadas en establecimientos hospitalarios tendrán derecho a recibir asistencia religiosa de su propia confesión de conformidad con las normas del presente reglamento" (Art. $4^{\circ}$ ). ¿Quiere decir esto, que el enfermo de religión católica, no puede, en caso de necesidad, recurrir al rabino, para la oración de los salmos?.

El Art. $5^{\circ}$ exige la solicitud expresa del enfermo para recibir asistencia religiosa. Esto, en caso de aplicarse, plantea graves restricciones a la libertad religiosa de aquellos que se encuentran impedidos de formular este requerimiento, o que lo han formulado tácitamente, toda vez que la misma disposición señala que "esta petición no podrá entenderse concedida de manera implícita".

La primera parte del Art. $6^{\circ}$ parece desconocer la dimensión colectiva de la libertad religiosa, cuando dispone que "la asistencia religiosa a los pacientes será 
entregada en forma individual y personal en su cama o en un lugar habilitado para ello, si su mé dico tratante ha autorizado tal desplazamiento".

El Art. $8^{\circ}$ del Reglamento recurre al artículo 42 del Código Civil para determinar quién puede, en caso de encontrarse impedido el paciente, prestar el consentimiento para que se le proporcione asistencia religiosa a éste, pero dicha norma no establece prelación entre los parientes del mismo grado y calidad ( $v$.gr. si el paciente tiene varios hermanos). Además, el Código Civil tampoco establece un "orden", por lo que no queda claro quién sería el llamado a prestar el consentimiento, a menos que se interprete "el orden que fija el artículo 42 del Código Civil" como el orden en que se mencionan los parientes, caso en el que de todos modos subsistiría la dificultad derivada de la pluralidad de éstos. El punto reviste importancia por la disparidad de cultos que pueden presentarse en la familia del enfermo.

\section{Declaración sobre las creencias religiosas}

La letra a) del artículo $6^{\circ}$ de la ley $n^{\circ} 19.638$ dispone que toda persona tiene la facultad de manifestar la creencia religiosa, 0 abstenerse de hacerlo.

Como consecuencia, el Art. $2^{\circ}$ del Reglamento expresa que: "Toda persona internada en un centro hospitalario tiene derecho a profesar la creencia religiosa que libremente ha elegido o no profesar ninguna, $y$, asimismo, a manifestar dicha circunstancia libremente 0 abstenerse de hacerlo sin que pueda ser coaccionado a actuar en un sentido contrario al que ha elegido a tal respecto".

Contradictoriamente, luego, el Art. $8^{\circ}$ contiene una disposición que expresa: "En el momento del ingreso del paciente se registrará en la ficha de admisión la confesión religiosa a que éste pertenece o la circunstancia de no pertenecer a ninguna, en su caso, y si desea recibir asistencia religiosa durante la estadía en el establecimiento".

En cambio, la norma citada, pudo prevenir las dificultades derivadas del Art. $5^{\circ}$ permitiendo al paciente, si lo desea, solicitar que se deje constancia de la religión que profesa, así se contaría con su consentimiento, para la asistencia, en caso de no estar consciente.

\section{4.- Uso de los lugares de culto}

El Art. 12 del Reglamento dispone que tratándose de centros asistenciales de salud de atención cerrada, "dichos establecimientos deberán permitir el uso por estos religiosos (se refiere a los ministros del culto) de las capillas o lugares de oración que posean". 
La autoridad parece ignorar que los lugares de culto mencionados pueden ser de propiedad privada, con lo que estaría afectando su derecho de dominio. Por otra parte si la expresión "posean" pretende exigir "posesión", obligaría a probar el corpus y el animus, a lo menos, antes de adoptar decisiones sobre el uso de los mismos.

Por otra parte, aún con prescindencia de quién sea el titular del derecho de dominio, conviene recordar lo que el Art. 586 del Código Civil dispone: "las cosas que han sido consagradas para el culto divino, se regirán por el derecho canónico".

\section{5-. Reglamento y "entidades religiosas" de la Ley ${ }^{\circ} 19.638$}

El Art. $9^{\circ}$ define las "entidades religiosas", como "las entidades integradas por personas naturales que profesan la misma fe", reconociéndoles, en el Art. 10, la facultad de prestar asistencia religiosa.

En este contexto, parece casi imposible pensar en algún grupo, secta o asociación, que resulte excluida del concepto de "entidad religiosa".

De este modo, el Reglamento crea una institucionalidad propia para el reconocimiento de los entes religiosos y sus ministros, al margen de la Constitución Política, la ley $n^{\circ} 19.638$ y el Reglamento para el Registro de Entidades Religiosas de Derecho Público.

Al no exigir personalidad jurídica a los referidos entes, obliga a la autoridad de salud a transformarse en perito, intérprete y juez, de las normas propias de éstos, para comprobar la representatividad de quienes pretendan acreditar a los ministros del culto que prestarán la asistencia religiosa.

Por otra parte, es discutible que el concepto de "entidad religiosa" incluya a la Iglesia Católica, con lo que el Art. $9^{\circ}$ resultaría discriminatorio e inconstitucional, ya que el Art. $5^{\circ}$ de la ley $n^{\circ} 19.638$ resulta aplicable sólo para la referida ley, y además, el Art. 20 del mismo texto legal se refiere a "las iglesias, confesiones e instituciones religiosas", y no a "entes religiosos" o "entidades religiosas".

Finalmente, el Reglamento carece de rigurosidad al momento de establecer quiénes pueden prestar asistencia religiosa. En efecto, el Capítulo III se titula "De la concurrencia de sacerdotes, pastores y ministros a los centros hospitalarios"; luego el inciso primero del Art. 10 señala que las entidades religiosas deben inscribir a "los sacerdotes, ministros o pastores de su culto", a quienes llama genéricamente "religiosos", en el inciso $2^{\circ}$; el inciso $1^{\circ}$ del Art. 12 menciona al "sacerdote, ministro o religioso", y luego, en el inciso $2^{\circ}$ se refiere a ellos como "religiosos". 


\section{LEY N¹9.687, SOBRE OBLIGACIÓN DE SECRETO}

Como consecuencia de las propuestas de la llamada "Mesa de Diálogo", que reunía a representantes de las iglesias, uniformados, abogados de derechos humanos y funcionarios públicos, para resolver el tema de los detenidos desaparecidos durante el gobierno militar, se promulgó la ley $n^{\circ} 19.687$, publicada en el Diario Oficial del 6 de Julio de 2000.

El inciso $1^{\circ}$ del Artículo único dispone: "Los pastores, sacerdotes o ministros de culto de iglesias, confesiones o instituciones religiosas que gocen de personalidad jurídica, los miembros de la Gran Logia de Chile y de la B nai B rith de Chile ..., que dichas instituciones determinen, estarán obligados a mantener reserva únicamente respecto del nombre y los datos que sirvan para identificar a quienes les proporcionen o confíen información útil y conducente para establecer el paradero y destino de los detenidos desaparecidos a que hace referencia el artículo $6^{\circ}$ de la ley $N^{\circ} 19.123^{\prime \prime}$.

Esta "obligación", es también un "derecho" que puede hacer valer quien ha recibido la información, a fin de no declarar respecto a la identidad del informante. Así, el inciso $4^{\circ}$ del Artículo Unico, dispone que "dichas personas se entenderán comprendidas en el N² del artículo 201 del Código de Procedimiento Penal".

Conforme a esta ley sólo determinadas personas podian recibir la información bajo esta particular forma de secreto. El inciso $1^{\circ}$ del Artículo Unico expresa: "Los pastores, sacerdotes ${ }^{4} \circ$ ministros de culto de iglesias, confesiones 0 instituciones religiosas que gocen de personalidad jurídica, los miembros de la Gran Logia de Chile y de la B'nai B'rith de Chile..., que dichas instituciones determinen", "y el inciso $2^{\circ}$ dispone que "la determinación de las personas a que alude el inciso anterior será reservada y deberá contenerse en un registro que deberán llevar las instituciones mencionadas, a cargo de un ministro de fe designado para tal efecto" ${ }^{5}$. En consecuencia, la persona que recibió la información debería estar incluida en el registro aludido, antes de recibir la confidencia.

El secreto que ampara esta ley tiene limitación en el tiempo. Conforme al inciso $5^{\circ}$ del Artículo Unico, sólo resulta aplicable a la información recibida dentro del plazo de seis meses, contados desde la fecha de publicación de la misma.

\footnotetext{
${ }^{4}$

Tratándose de los sacerdotes o presbiteros católicos, el secreto o reserva de esta ley, no debe confundirse con el que se refiere a la información recibida a propósito del sacramento de la reconciliación o confesión.

Si el objetivo perseguido era obtener información sobre los detenidos desaparecidos, parece contradictorio que la identidad de quienes están habilitados para recibirla sea "reservada", lo razonable sería darle la mayor publicidad a tal carácter. La importancia del registro es que en el futuro permitirá determinar quiénes pueden invocar el secreto creado por esta ley, para no ser obligados a prestar declaración.
} 
Esta información, debía ser entregada al Presidente de la República, "a más tardar al vencimiento del plazo de seis meses" antes indicado.

\section{LA TRANSFORMACIÓN DE ENTIDADES RELIGIOSAS}

A pesar que las iglesias evangélicas buscaron, con la aprobación de la ley $n^{\circ} 19.638$, mejorar su estatuto jurídico, asimilándose a la Iglesia Católica, los legisladores al parecer olvidaron la existencia previa de cientos de estas iglesias, que habían sido constituidas al amparo del Código Civil y el Decreto Supremo n¹10, de 1979, del Ministerio de Justicia, y que gozaban de personalidad jurídica de derecho privado.

Así, la referida ley y su reglamento, no contemplaron la posibilidad, para dichas iglesias, de acogerse al nuevo estatuto, sin necesidad de constituirse nuevamente.

En consecuencia, cualquier iglesia, regida por el Título XXXIII del libro I del Código Civil, que desee beneficiarse con el estatuto de persona jurídica de derecho público, debería constituirse, por segunda vez, conforme, ahora, a la ley $n^{\circ} 19.638$ y su reglamento.

Al comentar el Reglamento para el Registro de entidades religiosas de derecho público, criticábamos que sus normas pretendiesen regular la "constitución" de entidades religiosas, esto es, de iglesias, confesiones e instituciones religiosas. A propósito de las iglesias con personalidad jurídica de derecho privado, la contradicción entre la ley y el reglamento quedará aun más en evidencia.

Si quienes se inscriben para obtener personalidad jurídica de derecho público, son las "entidades religiosas", esto es, "las iglesias, confesiones e instituciones religiosas de cualquier culto" (Arts. $4^{\circ}$ y $5^{\circ}$ de la ley $n^{\circ} 19.638$ ), entonces, debería aceptarse que una iglesia constituida al amparo del Código Civil, también puede inscribirse.

Pero, si una iglesia, con personalidad jurídica de derecho privado, puede inscribirse en el registro, no se entiende por qué debería "constituirse" nuevamente, como lo exige el Art. $2^{\circ}$ del Reglamento. Por otra parte, la inscripción en el Registro, y la consecuente obtención de personalidad jurídica de derecho público, daría lugar a un verdadero fenómeno jurídico, porque una misma iglesia, gozaría, a la vez, de personalidad jurídica de derecho privado y de derecho público.

\footnotetext{
${ }^{6}$ Inciso $6^{\circ}$ del Artículo Unico.

${ }^{7}$ Así parecen admitirlo el Art. $8^{\circ}$ y la letra b) del Art. $4^{\circ}$ del Reglamento.
} 
Un caso real nos ayudará a percibir mejor el laberinto creado por la nueva regulación.

El 11 de enero de 2002, se publicó en el Diario Oficial, el Decreto Supremo $n^{\circ} 960$, del Ministerio de Justicia, del 22 de octubre de 2001, que aprobó la reforma de estatutos, el acuerdo de disolución, y canceló la personalidad jurídica a la "Iglesia Evangélica Pentecostal", de Santiago.

El único considerando del decreto, expresa: "Que los miembros de la Corporación "Iglesia Evangélica Pentecostal", se han constituido como entidad religiosa de derecho público al amparo de la ley 19.638, publicada en el diario Oficial N³6.488, de fecha 14 de octubre de 1999, y su Reglamento, Decreto Supremo N³03. de Justicia, de 2000, circunstancia que constituye fundamento calificado y suficiente para aprobar su reforma de estatutos y acuerdo de disolución y para cancelar la personalidad jurídica ...".

Llama la atención que el decreto exprese que "los miembros de la Corporación "Iglesia Evangélica Pentecostal", se han constituido como entidad religiosa de derecho público al amparo de la ley $n^{\circ} 19.638^{\prime \prime}$. Según esto, ambas personas jurídicas tendrían los mismos integrantes, y quienes constituyeron la nueva entidad religiosa, en este caso, una iglesia, fueron aquellos que formaban parte de la corporación de derecho privado.

En consecuencia, entre el nacimiento de la persona jurídica de derecho público, y la extinción de la corporación de derecho privado, coexistieron dos personas jurídicas, que se arrogaban representar una misma realidad, esto es, la Iglesia Evangélica Pentecostal.

Finalmente, y como era previsible, el $\mathrm{N}^{\circ} 2$ del decreto en comento, dispuso que "los bienes y el patrimonio (sic) de la entidad disuelta" pasarán a la "Iglesia Evangélica Pentecostal", la nueva iglesia, ahora con personalidad jurídica de derecho público.

\section{UN CASO DE REGRESIÓN JURÍDICA}

El 9 de enero de 2002 se publicó en el Diario Oficial el Decreto Supremo N864, del 7 de septiembre de 2001, del Ministerio de Justicia que dispone la cancelación de la personalidad jurídica de la Sociedad de Beneficencia de Señoras de Cauquenes.

8

El Art. $8^{\circ} \mathrm{del}$ Reglamento del Registro de Entidades de Derecho Público, dispone que "no podrà registrarse las iglesias, confesiones e instituciones religiosas cuyo nombre completo sea igual o tenga notoria similitud gráfica y fonética al de otra legalmente existente en el territorio nacional, a menos que ésta lo autorice expresamente, mediante escritura pública". 
Este acto administrativo no habría llamado nuestra atención, a no ser por su considerando $4^{\circ}$ que expresa: "según lo dispone el artículo 32, inciso segundo de los estatutos de la "Sociedad de Beneficencia de Señoras de Cauquenes", acordada la disolución, los bienes de la entidad pasarán previo inventario público a la Congregación de Religiosas Hospitalarias del Sagrado Corazón de Jesús, entidad que no cuenta con personalidad jurídica otorgada por este Ministerio".

¿Qué finalidad persigue la frase destacada?. Al contrario de lo que pareciera afirmar el decreto, la mayoría de las personas jurídicas existentes no cuentan con personalidad jurídica otorgada por dicho Ministerio: sindicatos, asociaciones gremiales, sociedades civiles y comerciales, personas jurídicas extranjeras, personas jurídicas de derecho público, etc.

¿Habrá que atribuirle el carácter de una simple constancia de carácter burocrático, estampada rutinariamente?.

Desconocemos el propósito de la constancia, sin embargo, parece preocupante que ella se consigne, a propósito de una congregación religiosa de la Iglesia Católica. EI Ministerio de Justicia no podía ignorar que el Art. $19 n^{\circ} 6$ de la Constitución Política de 1980 y el Art. 20 de la ley $n^{\circ} 19.638$ reconocen la personalidad jurídica de derecho público de las personas jurídicas erigidas por esta.

A propósito de este decreto, nos viene a la memoria el caso de la Congregación de las Hermanitas de los Ancianos Desamparados. Esta congregación diocesana, creada y dependiente del Obispado de Antofagasta solicitó al Presidente de la República, don Arturo Alessandri Palma, gestor de la Constitución Política de 1925 y negociador de la separación entre la Iglesia y el Estado, que se le concediera personalidad jurídica en conformidad al Código Civil y al Decreto Reglamentario de 31 de Octubre de 1925.

Por Decreto Supremo de fecha 2 de Diciembre de 1936, el Presidente de la República, denegó la solicitud, con el siguiente fundamento: "Que según lo dispuesto en el art. 547 del Código Civil, la corporación de que se trata es una comunidad religiosa a la cual la ley le acuerda el carácter de persona jurídica de derecho público; Que ni la constitución de estas corporaciones ni la aprobación de sus estatutos están sujetas a las disposiciones del Título XXXIII del Libro I del Código Civil; Que las reglas anteriormente citadas se refieren únicamente a las corporaciones de derecho privado, por cuanto el mismo artículo 547 del Código Civil excluye de sus preceptos a las Iglesias y Comunidades Religiosas, las que se rigen por leyes y reglamentos especiales; ...Que de acuerdo con los considerandos enunciados y las disposiciones legales señaladas, la institución religiosa solicitante goza de personalidad jurídica propia acordada por 
disposición expresa de la ley en virtud de su carácter de corporación pública, siendo innecesario por este motivo el otorgamiento del beneficio que solicita...".

\section{IGLESIAS EVANGÉLICAS Y CENSO NACIONAL 2002}

Recientemente se sucitó una polémica, a través de la prensa, a propósito de la formulación de la consulta relativa a la religión que profesa el encuestado.

En el censo de 1992, entre las alternativas que se ofrecían, estaban las de "protestante", y "evangélico". Naturalmente, la primera opción se refería a las iglesias más antiguas, nacidas de la Reforma, como la Anglicana y Luterana, y la otra aludía a las sucesivas divisiones de las anteriores.

Para el censo del año 2002, se suprimió la opción "protestante", y se agregaron las de "mormón" y "testigo de Jehová", permaneciendo la de "evangélico".

Esta última opción pretende representar a la totalidad de las iglesias surgidas de la Reforma. Considerando las diferencias existentes entre las innumerables denominaciones, la decisión no pareció acertada.

Es un hecho que no existe "la Iglesia Evangélica", como concepto que permita incluir a la totalidad del fenómeno asociativo religioso surgido a consecuencia de la Reforma de Lutero. Tal institucionalidad común no existe. Por eso se emplea la expresión "iglesias evangélicas".

Por lo demás, en el Censo 2002 se ha privilegiado la vinculación a una creencia, más que la adhesión eclesial, consultando por la religión que se profesa, y no la iglesia a la que se pertenece.

Respecto de la percepción de los propios "evangélicos", debe tenerse presente, que en 1977 las iglesias evangélicas no adscritas al Consejo de Pastores, dirigieron una carta al Presidente de la República en la que negaban la existencia de una Iglesia Evangélica, señalando que "las existentes superan el número de 300 denominaciones, y cualquier afirmación en tal sentido es inexacta y adolece de desinformación" (Humberto Lagos Lagos: "Crisis de la esperanza").

Sostener la adhesión a la Biblia, como criterio para reunir a evangélicos, de todas las denominaciones, y protestantes, en el censo, no parece realista y resulta contradictoria con la redacción actual de la consulta, en la que se indica como opciones

${ }^{9}$ ESTÉVEZ GAZMURI, Carlos, Elementos de Derecho Constitucional, Santiago de Chile, 1949, pp.112 y 113. 
separadas a los Testigos de Jehová y a los Mormones, que también presentan dicha adhesión.

Por lo demás no sólo los nombrados, también los católicos aceptan la Biblia como última palabra, el desacuerdo se produce en la interpretación de los textos.

La futura consulta del censo es un avance respecto del último, pero pudo ampliar la información. La Encuesta nacional CERC AB.1989, consultaba por la religión profesada, y distinguía: Evangélica, E. Bautista, E. Metodista, E. Pentecostal y Adventista (INJ 1992).

Finalmente, cuando en los diarios se afirma que quienes no respondan a las preguntas del censo serán sancionados, parece olvidarse que el Art $6^{\circ}$, letra a) de la ley 19.638, reconoce a toda persona el derecho de profesar la creencia religiosa que libremente elija, manifestarla libremente o abstenerse de hacerlo. 